\title{
Evaluation of the Simple View of Reading in an EFL Context: An Additive or Product Model?
}

\author{
Atefeh Ghaedsharafi \\ Islamic Azad University, Shiraz Branch \\ 339, Jadid Qoran Street, Shiraz, Iran \\ Tel: 98-711-227-9587_E-mail: sharafi_5256@yahoo.com \\ Mortaza Yamini (Corresponding author) \\ Islamic Azad University, Shiraz Branch \\ 61, Kucheh 14, Daneshgah Street, Shiraz 7194753837, Iran \\ Tel: 98-711-646-2699 E-mail: myamini@rose.shirazu.ac.ir
}

Received: March 19, 2011 Accepted: April 15, $2011 \quad$ doi:10.5539/ijel.v1n2p196

\begin{abstract}
This study attempted to find the relationship among decoding skill (DS), reading comprehension (RC) and listening comprehension (LC) in an EFL context to evaluate Gough and Tunmer's (1986) Simple View of Reading $(S V R)$ in which Reading Comprehension $=$ Decoding $\times$ Listening Comprehension. To this end, 85 female students studying English as a foreign language (EFL) at a Language Institute in Shiraz were asked to participate in the study. The sample was homogenous with regard to their English level. Through a multiple-choice cloze test, multiple-choice listening test and a word and non-word reading assessment, RC, LC and DS were measured respectively. To find out if reading comprehension equals DS $\times$ LC, correlation analysis and simple linear regression analysis were used. The results supported the validity of the simple view of reading
\end{abstract}

Keywords: Reading, Listening, Decoding, Phonological awareness, Dyslexia, Hyperlexia, Garden variety disability

\section{Introduction}

Decoding (D) is defined as the ability to convert written material into a phonetic code (Perfetti, 1985). It is in fact concerned with symbol-sound relationship. According to Constantinidou and Stainthorp (2009), phonological awareness secures decoding ability and that phonological deficits cause failure to acquire adequate word recognition. Slow word-reading rate may be an additional defining characteristic of reading disability. Chen and Vellutino (1997) stated that decoding is a "moderator variable that significantly affects the relationship between reading comprehension and listening comprehension" (p. 18).

Listening comprehension (LC), according to Morley (1972), is not only concerned with basic discrimination of the sound, but also involves extracting information, remembering it, and processing it or mediating between sound and meaning. Listening comprehension in L2 is said to be a "process of receiving, focusing attention on, and assigning meaning to aural stimuli" (Fang, 2008, p. 24). Goss (1982) defines LC as the process of taking what is heard and organizing it into words, phrases, sentences, or other linguistic units from which the listener can extract the meaning. O'Malley and Chamot (1989) consider LC as "an active and conscious process in which the listener constructs meaning by using cues from contextual information and existing knowledge, while relying upon multiple strategic resources to fulfill the task requirement" (p. 420).

Reading comprehension (RC), the base of learning, is a complex process. $\mathrm{RC}$ is the application of a skill evolved for other purposes (listening or oral comprehension) to a new form of input (text). Unlike listening comprehension, reading comprehension is not something for which our brains have evolved. Reading comprehension is challenging and requires intentional instruction. Humans have been doing oral comprehension for 100,000 years or more (Donald, 1991), and virtually all humans do it; reading comprehension has only been practiced for 5,000 years, and for most of that time most humans did not do it (Olson, 1994). 
Thus, it would not be surprising to assume that RC depends on LC. Furthermore, the relationship between decoding and RC cannot be denied. However, the nature of the relationship should be clarified. Do we have just a linear relationship and $\mathrm{RC}=\mathrm{D}+\mathrm{LC}$, or $\mathrm{RC}$ is a product of the other variables $(\mathrm{RC}=\mathrm{D} \times \mathrm{LC})$ ? If the summation is taken to be true, when one of the variables is zero, $\mathrm{RC}$ will equal the other variable. However, in the product model, if one of the elements is null, the product will be zero. In other words, it will not be possible for a reader to understand a text if $\mathrm{s} / \mathrm{he}$ has no skill in either listening or decoding. It is this aspect of reading that the present study concerns itself with.

What makes the present study different from other studies of the same type is that previous researchers mostly concerned themselves with reading in the first language albeit some reports on certain bilinguals are also available, but the present study is concerned with reading comprehension in the context of learning English as a foreign language (EFL). It is true that learners may bring certain skills from their mother tongue into the EFL environment, yet there are aspects that can be peculiar to the special situation that a foreign language may create for the learner. Therefore, it sounds sensible to investigate the applicability or validity of the simple view of reading (SVR) in an EFL context.

\section{Views on SVR}

Aarnoutse, Leeuwe, Voeten and Oud (2001) maintain that according to the simple view of reading, reading comprehension depends on two components, decoding and listening comprehension and these components are necessary for reading success but neither one is sufficient by itself. According to Gough and Tunmer (1986), "reading disability could result in three different ways: from an inability to decode, an inability to comprehend, or both ... the first is what is usually called dyslexia, the second hyperlexia, and the third we call garden variety disability" (p. 7). Their study of the relationship between decoding and comprehension in the first language (L1) led to the simple view of reading as $\mathrm{RC}=\mathrm{D} \times \mathrm{LC}$, which was later confirmed by Hoover and Gough (1990). In this connection, Yamada (2002) stated that if "listening comprehension is kept well within the normal range, reading comprehension is highly correlated with word decoding", but when listening comprehension is poor, "children would be poor readers, however good they may be at reading words" (p. 253).

Studying hydrocephalic children, Barnes, Faulkner and Dennis (2001) found that they decoded words better than they understood what they read in their first language. They compared speed of word decoding in 33 children with hydrocephalus and 33 controls matched on the basis for age, grade, and word decoding accuracy. The children with hydrocephalus were as fast as controls in reading words, but decoding speed did not contribute to reading comprehension beyond word decoding accuracy. The reading comprehension deficits of good decoders with hydrocephalus were not related to early-stage processing deficits in word decoding. They stated that comprehension deficits in hydrocephalic children may be related to discourse or text, so semantic processing of words and sentences may be intact. On the other hand, such problems in meaning construction would have negative effects on both sentence-level processing and discourse processes such as inferencing and text integration. According to Barnes and Dennis (1996, 1998, as cited in Barnes, Faulkner \& Dennis, 2001, p. 41), "Good decoders /poor comprehenders with hydrocephalus also have inferencing difficulties in reading and listening even when vocabulary and syntactic skills are intact" .

Georgiou, Das and Hayward (2009) conducted a study to evaluate SVR with a sample of First Nations children, known to have average decoding and listening comprehension but poor reading comprehension. In addition, they examined the contribution of naming speed and phonological awareness to reading comprehension beyond the effects of decoding and listening comprehension. The children showed poor reading comprehension despite average performance in decoding and listening comprehension, a finding that challenged the simple view of reading. The results also revealed that an additive model $(\mathrm{D}+\mathrm{C})$ fitted the data equally well as a product model $(\mathrm{D} \times \mathrm{C})$. Neither naming speed nor phonological awareness accounted for unique variance.

Dreyer and Katz (1992) tested the SVR with a group of monolingual English-speaking third graders and reported that there was "better evidence for a model based on the sum of decoding and listening comprehension $(\mathrm{R}=\mathrm{D}+$ L) than a model based on primarily on the product of these two variables" (p. 163). However, when they studied the same group of students after two years, their data analysis supported the product model. They concluded, "Thus the results of our analysis again provided mixed evidence for The Simple View" (p. 163).

Lee and Wheldall (2009) examined the simple view of reading in Malay language. A sample of 117 beginning first-year readers attending Malaysian schools were assessed, after 6 months of initial instruction in reading and reading-related skills to determine (a) the contributions of decoding and listening comprehension to reading comprehension in Malay; (b) which model, the multiplicative model or the additive model, of the simple view of reading contributes more toward the variance in reading comprehension; and (c) whether adding the speed of processing factor to the multiplicative model improves its power to predict reading comprehension among 
beginning readers in Malay. Results indicated that reading comprehension was largely explained by decoding, with listening comprehension adding only a small amount to the variance accounted for. The additive model including the summation of decoding and listening comprehension was found to be a better predictor of reading comprehension. Results also showed that speed of processing did not account for unique variance in reading comprehension.

Gottardo and Mueller (2008) studied L2 reading comprehension in a group of young Spanish-speaking students being educated in English. The study looked for factors in L2 reading comprehension of 131 first graders and followed 79 of them into the second grade. The structural equation modeling used in the study revealed that a 5-factor model including L1 and L2 phonological awareness, L1 and L2 oral language proficiency, and word reading in L2 best fitted the model of L2 reading comprehension. L1 and L2 phonological awareness proved to be two separate but related constructs, whereas L1 and L2 oral language proficiency were found to be two separate constructs. The best predictors of L2 reading comprehension were L2 oral language proficiency and word reading, thus confirming the validity of the simple view of reading.

In sum, the studies reviewed here present controversial results as regards the nature of the relationship between reading comprehension and its related factors of decoding and listening comprehension. Furthermore, they are mostly concerned with L1 reading or L2 in young bilinguals. Thus, there remains a place for a study of SVR in a context where English is learned as a foreign language by some adolescents and adults.

\section{Method}

\subsection{Participants}

This study was conducted with 85 female students at a language institute in Shiraz. The participants were native speakers of Persian and they were studying English as a foreign language (EFL). The students ranged in age from 15 to 25, but they were homogenous with regard to their English level. They had already passed four terms at the institute, each term lasting for three months with four hours of instruction per week. At the time of study, they were all at their fifth term, studying the same textbook in different sections.

\subsection{Instruments}

The instruments used in this study included a multiple choice cloze test, a multiple choice listening test and a word and non-word reading assessment. The multiple choice cloze and listening tests were used to measure the participants' reading comprehension and listening comprehension respectively, and word and non-word reading assessment was used to estimate their decoding skill.

\subsubsection{Multiple choice cloze test}

Some researchers emphasize that cloze procedures measure reading comprehension. Rye (1982, as cited in Lu, 2006) declared that there was eighty-five percent overlap between the cloze test and reading comprehension test. Neville (1984, as cited in Lu, 2006, p. 25) stated, "If we can restore correctly the words omitted from a passage, we must have a good grasp of its comprehension". Thus, a reader's ability to complete the mutilated passage would be an indication of his/her reading comprehension ability in general (Farhady, Jafarpur \& Birjandi, 2006).

The cloze test used in this study was prepared by Nowroozzadeh (2000) with 25 blanks and every seventh word deleted. She stated that the passage "was excerpted from Reading Power (Science Research Associates Inc, 1990), complied by Don H. Parker" (Nowroozzadeh, 2000, p. 25).

Before the M-C cloze test was administered to the participants, the instructions were read aloud to them to ensure that they understood the nature of the test. The time allocated to the test was about 25 minutes. It was very easy to score the test. Every correct answer was given one point and the sum of the correct responses constituted the total score.

\subsubsection{Multiple choice listening test}

From the book Listening to TOEFL (ETS, 1989), designed to evaluate the listening comprehension of non-native speakers of English, 20 items were chosen. The test was administered to the participants of the study. The students listened to short conversations between two people. At the end of each conversation, which was played only once, a third person asked a question about the conversation. The students had to find the best answer to the questions among the choices presented to them in written form.

\subsubsection{Word and non-word reading assessment}

In recent research, decoding is defined as phonological awareness and it is measured through word and non-word reading. For example, to estimate decoding ability, Hagtvet (2003) asked the children to read thirteen words of different lengths and, nine short non-words and timed the reading. Similarly, in the present study, a list of 15 
non-words prepared by Yamini (1997), and 15 English words with different lengths was used to estimate the participants' decoding skill. The participants were asked to introduce themselves and then read the words as accurately and quickly as they could and reading was recorded electronically.

\subsubsection{Issues of reliability and validity}

As was already mentioned, the M-C cloze test was taken from Nowroozzadeh (2000). In her research, she measured the validity and reliability of the test and stated, "The validity coefficient was based on the coefficient between the participants' score on the CUPT [Cambridge University Placement Test] and the M-C cloze test" (p. 27). And the coefficient was 0.94 . To estimate the reliability of test scores, the correlation coefficient between two sets of scores obtained from two administrations of the same test to the same group was used. The tes-retest reliability reported by Nowroozzadeh (2000) was 95 .

To estimate the reliability of the M-C listening comprehension in the present study, Cronbach's alpha was used. The result, as shown in Table 1, was .799.

With regard to the decoding test, intra-rater reliability was used to measure the reliability of the decoding skill measurement. Thirty responses to the DS test were chosen randomly and rescored. Then, the correlation between the two sets of scores was calculated, which turned out to be 0.976 (Table 2).

\subsection{Procedures for data collection}

The M-C cloze test was distributed among the students at their classroom hour during the spring term, 2010. The instructions were read aloud to them and they were notified that the allocated time was 25 minutes. The next session in the same class the M-C listening test was distributed and the recorded part of listening was played for them and they were asked to tick the best answer on their paper. The administration took about 20 minutes in each class. Decoding skill was assessed by means of a test of word and non-word reading, before the beginning of each class or after the end. The participants, one by one, were asked to read a list; containing 15 words (English) and 15 non- words as accurately and quickly as they could. Reading was recorded and timed electronically.

To measure the decoding skill, the score of each word was defined; one point was given to each vowel and one point to each problematic consonant, so pronouncing one vowel or a problematic consonant correctly, provided the participants with one point. Thus, the summation of all the points was the total score. In this test, the time of reading was important, so it was timed. Then, the total grade of reading the list was divided by the measured time so that the estimation of decoding skill for each participant was obtained.

\subsection{Procedures for data analysis}

After gathering the data, the participants' reading comprehension (RC), listening comprehension (LC) scores were calculated. Scoring was very easy; every correct answer was given one point and the sum of correct answers was taken as the total score. The obtained results of decoding measurement were converted to Z-scores. Correlational analysis was used to measure the degree of relationship between RC, LC and DS. Then, a simple linear regression was used to see if the product model $(\mathrm{D} \times \mathrm{LC})$ or additive model $(\mathrm{D}+\mathrm{LC})$ best predicted reading comprehension.

\section{Results}

To fulfill the objectives of the study, some statistical analyses were run. In the following sections, the descriptive statistics of the variables, correlational results, regression and ANOVA tables are provided.

\subsection{Descriptive statistics}

The obtained data were subjected to descriptive statistics and the mean score, standard deviation, maximum and minimum of the scores in M-C cloze test, M-C listening test and decoding skill were found. Table 3 presents the results.

\subsection{Correlation analyses}

To determine the degree of going-togetherness of reading comprehension, listening comprehension and decoding, correlational analyses were run for all participants as one group. Table 4 displays the correlations between RC, LC and DS. As can be seen, there is no correlation between LC and decoding skill, but the correlation between RC and DS is .419 which is significant at the .01 level. This shows a positive correlation between the two variables. This table also reveals that $\mathrm{RC}$ and $\mathrm{LC}$ are positively correlated $(\mathrm{r}=0.427)$ at the .01 level of significance. Thus, when D and LC by themselves correlate with RC, it can be concluded that the sum and product of the two variables would also correlate with it. This is confirmed by the regression analysis reported in the following section. 


\subsection{Regression analysis}

A simple linear regression analysis was run to find out the better predictor of reading comprehension. To this end, first the scores of the participants in decoding and LC were once multiplied and once added together. Then the sum and product results were used to predict RC. Tables 5, 6 and 7 display the summary, ANOVA and coefficients. Table 5 shows that $\mathrm{R}^{2}$ is .33 . So, about $33 \%$ of the variance in $\mathrm{RC}$ can be predicted by the variances in DS + LC and DS $\times$ LC. This can be confirmed when we consider the significance level of the ANOVA reported in Table 6, which indicates that the result is significant at the .001 level. The significance column in Table 7 tells us that only the variance in $\mathrm{DS} \times \mathrm{LC}$ is able to predict the variance in the dependent variable (RC). The beta value for DS $\times$ LC is .478 which means that one standard deviation unit change in the independent variable results in .478 units of change in RC.

\section{Discussion and conclusion}

In this study, it was found that DS and RC were positively correlated. This finding is in line with the findings of most of the studies in this domain (e.g. Gough \& Tunmer, 1986; Hoover \& Gough, 1990; Georgiou, Das \& Hayward, 2009; Dreyer \& Katz, 1992; Lee \& Wheldall, 2009; Gottardo \& Mueller, 2008). LC and DS were not correlated; there was no relationship between these two variables. This may be due to the fact that decoding was assessed through visual stimuli. However, if auditory stimuli had been used, the results could have been different.

A positive correlation was found between RC and LC. This finding is in line with the findings of Yamada (2002), and Hagtvet (2003), who reported a high correlation between LC and RC.

To examine the standard principle of reading comprehension some researchers conducted some studies to investigate the formula: Reading Comprehension $=$ Decoding $\times$ Listening Comprehension. Yamada (2002), Roch and Levorato (2009) confirmed this formula but Lee and Wheldall (2009) suggested that the summation of decoding and listening comprehension was a better predictor in reading comprehension. Georgiou, Das and Hayward (2009) declared that an additive model $(D+C)$ fitted the data in their research as equally well as a product model. In this study, carried out in an EFL context, regression analysis revealed that $\mathrm{D} \times \mathrm{LC}$ is a better predictor of RC. Thus, the validity of the simple view of reading: $\mathrm{RC}=\mathrm{D} \times \mathrm{LC}$ was confirmed.

Applied to real life situations, either of the models suggested here may find some support. When we assume RC $=\mathrm{LC} \times \mathrm{DS}$, if one of the elements in multiplication is zero, the whole product will be zero. This is true about some illiterate people who have perfect listening comprehension, but because they do not have the decoding skill, they cannot read and their RC is zero. However, in deaf people, who do not develop listening comprehension through ear, RC can develop. Furthermore, examples can also be found of some people who develop some decoding ability without really being able to assign meaning to what they read. There are some people who read their religious texts in a language other than their mother tongue, but they do not have enough comprehension to analyze the text semantically. These examples may justify the mixed results found in the literature.

The implication of the present study for the EFL classroom context is that in teaching reading we should not limit ourselves to visual stimuli and just silent reading. The importance of symbol-sound relationship and listening comprehension should also be taken into account. Reading can be taught with due attention to listening.

Finally, it should be mentioned that the results of the present study cannot be generalized because the sample was small and limited. We were just concerned with a group of EFL learners at the same level of proficiency, whereas students at different levels may perform differently. Further study with cross-sectional or longitudinal approach is needed to find out about the learners at different levels and see if change in the level of proficiency can have an impact on the results. Moreover, statistical analyses other regression may also be employed. For example, structural equation modeling or path analysis may shed more light on the subject.

\section{Acknowledgement}

The authors express their gratitude to the anonymous reviewers of the journal for their helpful suggestions.

\section{References}

Aarnoutse, C., Leeuwe, J. V., Voeten, M. \& Oud, H. (2001). Development of decoding, reading comprehension, vocabulary and spelling during the elementary school years. Reading and Writing: An Interdisciplinary Journal, 14(1-2), 61-86. doi:10.1023/A:1008128417862, http://dx.doi.org/10.1023/A:1008128417862

Barnes, M. A., Faulkner, H.J. \& Dennis, M. (2001). Poor decoding despite fast word decoding in children with hydrocephalus. Brain and Language, 76, 35-44. doi:10.1006/brln.2000.2389, http://dx.doi.org/10.1006/brln.2000.2389 
Chen, R. S. \& Vellutino, F. R. (1997). Prediction of reading ability: A cross-validation study of the simple view of reading. Journal of Literacy Research, 29(1), 1-24, doi:10.1080/10862969709547947, http://dx.doi.org/10.1080/10862969709547947

Constantinidou, M. \& Stainthorp, R. (2009). Phonological awareness and reading speed deficits in reading disabled Greek-speaking children. Educational Psychology, 29(2), 171-186. doi:10.1080/01443410802613483, http://dx.doi.org/10.1080/01443410802613483

Donald, M. (1991). The origins of the modern mind: Three stages in the evolution of culture and cognition. Cambridge MA: Harvard University Press.

Dreyer, L. G. \& Katz, L. (1992). An examination of "the simple view of reading". Haskins Laboratories Status Report on Speech Research, SR 111/112, 161-166. [Online] Available: www.haskins.yale.edu/sr/SR111/SR111_12.pdf (November 12, 2010)

ETS. (1989). Listening to TOEFL: An official TOEFL study aid. Princeton, N.J.: Educational Testing Service.

Fang, X. (2008). Listening comprehension in EFL teaching. China Foreign Language, 6(1), 539-8080. [Online] Available: http://www.linguist.org.cn/doc/ uc200801/uc20080105.pdf (January 15, 2010)

Farhady, H., Jafarpur, A. \& Birjandi, P. (2006). Testing language skills from theory to practice $\left(12^{\text {th }}\right.$ ed). Tehran: The Organization for Researching and Composing University Textbooks in Humanities.

Georgiou, G. K., Das, J. P. \& Hayward, D. (2009). Revisiting the "Simple View of Reading" in a group of children with poor reading comprehension. Journal of Learning Disabilities, 42(1), 76-84. [Online] Available: http:// www.eric.ed.gov/ (November 3, 2009)

Goss, B. (1982). Listening as information processing. Communication Quarterly, 30(4), 304-311. [Online] Available: $m$ www.eric.ed.gov (January 17, 2010)

Gottardo, A. \& Mueller, J. (2008). Are first- and second-language factors related in predicting second-language reading comprehension? A study of Spanish-speaking children acquiring English as a second language from first to second grade. Journal of Educational Psychology, 101(2), 330-344. doi:10.1037/a0014320, http://dx.doi.org/10. 1037/a0014320

Gough, P. B. \& Tunmer, W. E. (1986). Decoding, reading, and reading disability. Remedial and Special Education 7, 6-10. doi:10.1177/074193258600700104, http://dx.doi.org/10.1177/074193258600700104

Hagtvet, B. E. (2003). Listening comprehension and reading comprehension in poor decoders: Evidence for the importance of syntactic and semantic skills as well as phonological skills. Reading and Writing: An Interdisciplinary Journal, $16, \quad 505-539 . \quad$ doi:10.1023/A:1025521722900, http://dx.doi.org/10.1023/A:1025521722900

Hoover, W. A. \& Gough, P. B. (1990). The simple view of reading. Reading and Writing: An Interdisciplinary Journal, 2, 127-160. doi:10.1007/BF00401799, http://dx.doi.org/10.1007/BF00401799

Lee, L. W. \& Wheldall, K. (2009). An Examination of the Simple View of Reading among Beginning Readers in Malay. Reading Psychology, 30(3), 250-264. doi:10.1080/02702710802411364, http://dx.doi.org/10.1080/02702710802411364

Lu, G. (2006). Cloze tests and reading strategies in English language teaching in China. [Online] Available: http://etd.uwc.ac.za/usrfiles/modules/etd/docs/etd_init_1689_1177054866.pdf (June 10, 2010)

Morley, J. (1972). Improving aural comprehension. Ann Arbor, MI: University of Michigan Press.

Nowroozzadeh, N. (2000). Comparing the M-C cloze test and the C-tests as the measurement of proficiency in English. Unpublished master's thesis. Islamic Azad University, Shiraz, Iran.

O’Malley, J. M. \& Chamot, A. U. (1989). Listening comprehension strategies in second language acquisition. Applied Linguistics, 10(4), 418-437.

Olson, D. R. (1994). The world on paper: The conceptual and cognitive implications of writing and reading. Cambridge UK: Cambridge University Press.

Perfetti, C. A. (1985). Reading ability. New York: Oxford University Press.

Roch, M. \& Levorato, M. (2009). Simple View of Reading in Down's syndrome: the role of listening comprehension and reading skills. doi:10.1080/13682820802012061, http://dx.doi.org/10.1080/13682820802012061

Yamada, J. (2002). Neurological origins of poor reading comprehension despite fast word decoding? Brain and Language, 80, 253-259. doi:10.1006/brln.2001.2565 http://dx.doi.org/10.1006/brln.2001.2565

Yamini, M. (1997). A pedagogical approach to the pronunciation of English words. Unpublished Ph. D. dissertation. Allameh Tabatabaie University, Tehran, Iran. 
Table 1. Reliability statistics for listening test

\begin{tabular}{cc}
\hline Cronbach's Alpha & N of Items \\
\hline .799 & 20 \\
\hline
\end{tabular}

Table 2. Correlation between two sets of decoding scores

\begin{tabular}{lcc}
\hline & & Decoding2 \\
\hline Decoding 1 & Pearson Correlation & .976 \\
\cline { 2 - 3 } & Sig. (2-tailed) & .000 \\
\hline
\end{tabular}

Table 3. Descriptive statistics of reading, listening and decoding assessment

\begin{tabular}{cccccc}
\hline & $\mathrm{N}$ & Minimum & Maximum & Mean & Std. Deviation \\
\hline listening & 85 & 5.00 & 19.00 & 10.7294 & 3.04094 \\
\hline Reading & 85 & 7.00 & 22.00 & 13.2353 & 2.80156 \\
\hline Decoding & 85 & .26667 & 1.45902 & .7748050 & .27598039 \\
\hline Z-score (decoding) & 85 & -1.84121 & 2.47920 & .0000000 & 1.0000000 \\
\hline
\end{tabular}

Table 4. Pearson correlation between RC, LC and DS

\begin{tabular}{cccc}
\hline & & Reading & Z-score(Decoding) \\
\hline \multirow{2}{*}{ Listening } & Correlation & .427 & .065 \\
\cline { 2 - 4 } & Sig. (2-tailed) & .000 & .552 \\
\hline \multirow{2}{*}{ Reading } & Correlation & & .419 \\
\cline { 2 - 4 } & Sig. (2-tailed) & & .000 \\
\hline
\end{tabular}

Table 5. Model summary in regression analysis to predict RC from DS + LC and DS $\times$ LC

\begin{tabular}{ccccc}
\hline Model & $\mathrm{R}$ & R Square & $\begin{array}{c}\text { Adjusted R } \\
\text { Square }\end{array}$ & $\begin{array}{c}\text { Std. Error of } \\
\text { the Estimate }\end{array}$ \\
\hline 1 & $.574^{\mathrm{a}}$ & .330 & .313 & 2.32148 \\
\hline
\end{tabular}

a. Predictors: (Constant), listening multiplied by decoding, listening added to decoding

Table 6. ANOVA in regression analysis to predict RC from DS + LC and DS $\times$ LC

\begin{tabular}{ccccccc}
\hline & Model & Sum of Squares & df & Mean Square & F & Sig. \\
\hline 1 & Regression & 217.373 & 2 & 108.687 & 20.167 & $.000^{\text {a }}$ \\
\cline { 2 - 7 } & Residual & 441.921 & 82 & 5.389 & & \\
\hline & Total & 659.294 & 84 & & & \\
\hline
\end{tabular}

a. Predictors: (Constant), listening multiplied by decoding, listening added to decoding

b. Dependent Variable: reading

Table 7. Coefficients in regression analysis to predict RC from DS + LC and DS $\times$ LC

\begin{tabular}{cccccc}
\hline \multirow{2}{*}{ Model } & \multicolumn{2}{c}{$\begin{array}{c}\text { Unstandardized } \\
\text { Coefficients }\end{array}$} & $\begin{array}{c}\text { Standardized } \\
\text { Coefficients }\end{array}$ & $\mathrm{t}$ & \multirow{2}{*}{ Sig. } \\
\cline { 2 - 5 } & $\mathrm{B}$ & Std. Error & Beta & & \\
\hline (Constant) & 9.078 & .997 & & 9.102 & .000 \\
\hline DS+LC & .117 & .115 & .128 & 1.016 & .313 \\
\hline DS $\times$ LC & .337 & .089 & .478 & 3.798 & .000 \\
\hline a. Dependent Variable: Reading & & & & & \\
\hline
\end{tabular}

